\title{
The Study of Implementation of Safety Regulation for Children in Radiology Department
}

\author{
K. Ebrahim Nezhad Gorji ${ }^{1}$, S. Z. Hosseini Motlagh ${ }^{1}$, GH Ataei ${ }^{2}$, \\ ${ }^{1}$ Radiobiology \& Radiation Protection Faculty, Babol University of Medical Sciences, Babol, Iran \\ ${ }^{2}$ Faculty of Paramedical Sciences, Babol University of Medical Sciences, Babol, Iran
}

Email address:

golamrezaatae@yahoo.com (GH Ataei)

${ }^{*}$ Corresponding author

\section{To cite this article:}

K. Ebrahim Nezhad Gorji, S. Z. Hosseini Motlagh, GH Ataei. The Study of Implementation of Safety Regulation for Children in Radiology Department. Journal of Cancer Treatment and Research. Vol. 5, No. 3, 2017, pp. 48-50. doi: 10.11648/j.jctr.20170503.14

Received: February 19, 2017; Accepted: March 16, 2017; Published: May 24, 2017

\begin{abstract}
During the last few decades in different areas of the world the cancer incidence in children has increased. Children are major users of imaging services. Since children are more sensitive to radiation therefore dose minimization for them is important. The aim of this study is to assessment of safety for children in diagnostic radiology units. This cross-sectional study was conducted in three public hospitals of Khoramabad Lorestan province. 385 check lists in Shohadaye Ashyer, Madani, Taaminegtemaei hospitals are investigated. The checklist has five items with various questions around radiation protection and safety related to patients. The information achieved by the checklists was recorded and entered into SPSS (version 22). Among the 385 cases reviewed, 210 were boy $(54.6 \%)$ and 175 girl (45.4\%) patients. The mean age of patients was 6.14 years, ranging from 2 days to 12 years. Only Madani and Taaminegtemaei provided shield and warning posters. The use of shielding number in Shohaday eAshyer and Taaminegtemaeei hospitals is 87 (22.5\%) and Madani hospital is 194 (50.3\%). Patient dose reduction coincides with avoiding unnecessary exams, minimizing repeat images during exams, field size minimization and using appropriate shielding by performance this cases can be protect patient specially children. The use of gonad shielding in Shohadaye Ashyer hospital does higher rate than in Madani and Taaminegtemaeei hospitals.
\end{abstract}

Keywords: Radiation Protection, Children, Radiology

\section{Introduction}

Medical imaging that associate with ionizing radiation can have valuable diagnostic benefit, accompanied by probable danger [1]. Although minimizing radiation dose to medical exposure need consideration for all patient, concern for detrimental effect of radiation exposure is increased for the pediatric patient [2]. Children have a higher risk of developing neoplasm compared with adults receiving the equal dose, because of the life expectancy for children is longer than adult and the adverse effects of radiation have more time to manifest [3]. In different studies it is shown that the lifetime risk for children irradiated in that setting before age 10 is about 3 times higher than for individuals irradiated as adult [4]. Since children and young adult are more sensitive to radiation, the dose minimization for them is vitally important and radiation dose should be reduced to the least measure without the loss of diagnostic information [5]. Nowadays, a significant number of children are referred to imaging centers, but unfortunately radiography services for children have been abandoned by policy makers [6]. Especial attention should be given to the reducing dose of radiation when using imaging modalities for pediatric. One of the most important aspects of children imaging is with associate to the wide scope in patient size and weight, thus needing special consideration to optimization of radiation parameters and selection of the best imaging technique, such as proper positioning of patient, appropriate field of beam and proper collimation use of suitable shield, optimization of exposure condition, etc. [3]. In this study we surveyed the performance of technologist in radiography department, QC (Quality Control) of equipment and use of protection instrument for pediatric in 3 hospital. Our aim is to assess the safety regulation for children in diagnostic radiology units. 


\section{Method}

A cross-sectional study was done in hospitals of khoramabad, Iran. This information were collected and obtained by designing a checklist. The checklist has five items with various questions around radiation protection and safety related to patients. The first part contained information about name of hospital and radiology department. The second section was about patient demographic data like as age, sex and etc. The third section was about performance of technologist. The fourth section consisted of radiology equipment protection and final part pertinent $\mathrm{QC}$ of radiological devices. The age of children participated in this study was 2 to 12 years. The information achieved by checklist, was recorded and entered into SPSS (version 22).

\section{Result}

The data from a total of 3 hospitals is included in this paper. The response to survey was received from the following three hospitals: Shohadaye Ashyer, Madani, Taaminegtemaeei. Among the 385 cases reviewed, 210 cases were boys $(54.6 \%)$ and 175 cases were girls $(45.5 \%)$ patients. The mean age of patients was 6.14 years, ranging from 2 days to 12 years. Also field size minimization technique to provide the proper size using in the participating centers including: Shohadaye Ashyer (in 65.5\% of cases), Madani (in $54.79 \%$ of cases) and Taaminegtemaeei (in $63.95 \%$ of cases). Only Madani and Taaminegtemaeei provided shield and warning posters. The results showed the number of radiography was used shield in three hospitals, Shohadaye Ashyer 90 (23.3\%), Taaminegtemaeei 97 (25.1\%) and Madani 198 (51.4\%). The percent use of kind of shields in three hospitals showed figure1.

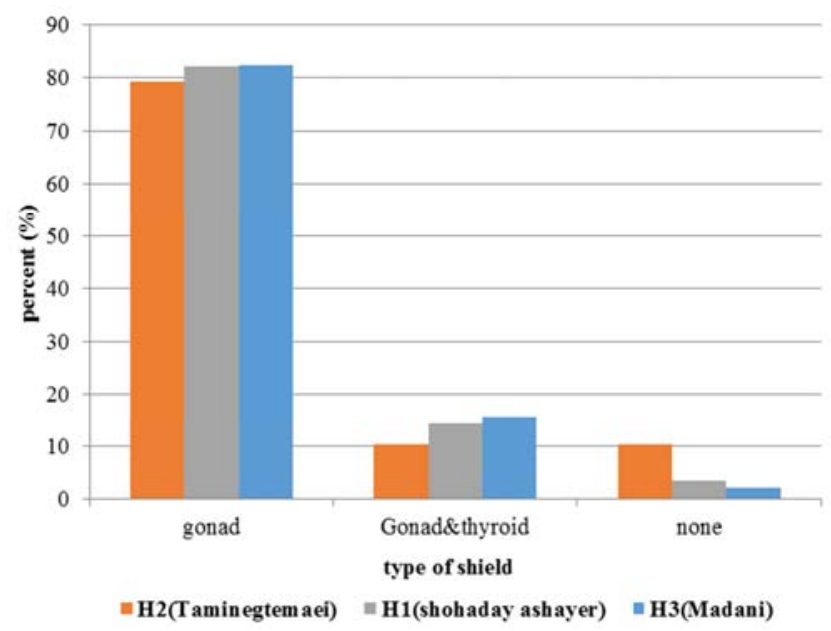

Figure 1. The percent use of type of shield in three hospitals.

The quality control tests that were carried out in all of hospitals included: the calibration of the radiology units, the lack of leakage ionizing beams and the consistency of optical field with radiation field.

\section{Discussion}

Radiation safety and the ALARA (as low as reasonably achievable) principle chiefly for pediatric, rightly attract consideration in medical literature [7]. Preventing unnecessary radiography exams, minimizing image retaking, using optimum technique of imaging, collimating the field of radiation and selecting appropriate shielding may result in patient dose reduction [8]. Reducing the size of FOV is possible choice that can reduce radiation dose without loss of image quality. Smaller FOV is leading to decrease the total effective dose. [9] According to one study that conducted in Yazd province in 2013, collimating the field of radiation was considered in $14.10 \%$ of cases [10] and in Debases and colleague survey in 2014 , the date showed $76-90 \%$ of chest Xray exams were lack of collimating of FOV [11]. Our data revealed that high attention to collimating FOV compared with survey that was mentioned. According to our study field size minimization technique using in the Shohadaye Ashyer hospital (in $65.5 \%$ of cases), Madani hospital (in $54.79 \%$ of cases) and Taaminegtemaeei hospital (in 63.95\% of cases)Although reduction of field size is recommended during pediatric X-ray examination, but it does not completely omit the exposure and use of proper shielding is essential [12].

Use of shielding is extremely important in minimizing exposure. The technologist can reduce exposure more than $90 \%$ by the proper use of shielding [13]. Some tissue has less resistance against the X-ray such as thyroid gland [9]. The national council on radiation protection and measurement (NCRP) state: "thyroid shielding shall be provided for children, and should be provided for adult, when it will not interfere with the exam." [14] The use of $\mathrm{Pb}$ thyroid shield for pediatric, cause a significant reduction in the radiation dose to thyroid by about $97 \%$ [12].

In one study that handled in Esfahan province in 2011, during the dental radiography of 184 patient, the use of thyroid shield were observed just in $4.5 \%$ of cases [15] and in the study that surveyed Javadzadeh et al. Rasht-Iran 2009, among the 110 patient that had dental radiography, the use of thyroid shielding were observed only in 1 case [16]. Our study showed just 54 cases in gonad \& thyroid shield.

The gonad shielding should be used to reduce the effect of radiation to gonad during Abdomen, Pelvis and Hip X-ray examination [17]. Covering the gonad with $1 \mathrm{~mm} \mathrm{~Pb}$ can reduce the radiation dose to tests $(95 \%)$ and ovaries $(50 \%)$ [18], [19]. Our data show, the use of gonad shielding in Shohadaye Ashyer hospital is higher rate than in Madani and Taaminegtemaeei hospitals. According to the study that carried out with Karami and colleague in Ahvaz, although in $64.3 \%$ of radiography unit at least one gonad shield was available but using of it was observed only in $2 \%$ of exam [20]. One of the main reasons of unnecessary radiation to patient in radiology unit is the lack of quality control program. Quality control program is the complement issue to each radiology unit [21]. Leakage beam is considered as one of the most harmful rays for patient and fortunately in our study no leakage beam was found in hospitals. 
Shahbazigahrooiy examined 7 radiology units in Chaharmahal Bakhtiary province and they reported 3 of them had a leakage beam because of they were been out of old [22]. According to our survey all of radiology units in 3 hospital have consistency of optical field with radiation field, while one study in Sistan and Balochestan province in 2011 reported, among 9 radiology unit that were investigated, all of them had a problem regard to consistency of optical field with radiation field [23].

In a study, performed in 25 units of Bushehr-Iran; 16 units lacked consistency of optical field with radiation field and 22 units lacked warning posters [24], whereas hospitals of our study have consistency of optical field with radiation field and only Madani hospital and Shohadaye Ashyer have warning posters. One of advantage of our study is determination of kind of radiographic examination that were accompanied by using of protection shielding and specifying the use of shielding by sex and range of age in pediatric, whereas according to Karami and Zabihzadeh in 2016, more of articles just reported general percentage of the use of shielding without determination of kind of radiographic exam and sex and age of patient [21]. In conclusion, regard to the ALARA (as low as reasonably achievable) principle, radiation dose should be reduced to the least measure without the loss of diagnostic information [9]. Thus, radiation dose can be reduced with pay more attention to accuracy of quality control program, use of warning posters, use of protection shielding and collimation of FOV.

\section{References}

[1] Joshua S. Broder, Donald P. Frush. Content and Style of Radiation Risk Communication for Pediatric Patients. J. jacr.2013.10.003.

[2] Anish Ghodadra, Stefano Bartoletti. Reducing Radiation Dose in Pediatric Diagnostic Fluoroscopy. J. jacr.2015.07.030.

[3] ICRP PUBLICATION 121: Radiological Protection in Pediatric Diagnostic and International Radiology. Annals of the ICRP 2013. 42 (2). 1-63.

[4] Halle. Giaccia; Radiobiology for the Radiologist (ed 6), Lippincott Williams and Wilkins, New York (2006), pp. 16-29 135-155, 216.

[5] National Council for Radiation Protection and Measurement. Radiation protection in dentistry, Bethesda, MD, 2004; pp. 14-27.

[6] Sandra A. Mathers, Helen Anderson, Sheila McDonald. A survey of imaging services for children in England, Wales and Scotland. Journal. 2011. 20-27.

[7] S L Fawcett, A C Gomez, S J Barter, M Ditchfield, P Set. More harm than good? The anatomy of misguided shielding of the ovaries. BJR. 85 (2012). e442-e447.

[8] Bushong, S. C. (2007). Radiologic Science for Technologist: Physic, Biology and Protection ( $9^{\text {th }}$ ed). St. Louis: Mosby.

[9] Xingminqu, Gangli, Zuyan Zhang, Xuchen Ma. Thyroid shield for radiation dose reduction during cone deam computed tomography scanning for different oral and maxillofacial regions. European Journal of Radiology 81 (2012). e376-e380.
[10] Chaparian A, ShamsiF, Heydari A. Assessment of awareness, attitude, and practice of radiographers about radiation protection in Yazd Province. TebeKar Journal (TKJ) 2013:5 (1):16-23 (Persian).

[11] Debess J, Johnsen K, Vejle Sorensen K, Thomsen H, Alborg Ost, Viborg D. Digital chest radiography: collimation and dose reduction. ECR 2015: European Society of Radiology (poster-Guidlin) 2015. p. 1-13.

[12] Vahid Karami, Mansour Zabihzadeh, MehrdadGholami, Nasim Shams, Zahra FazeliNezhad. Dose Reduction to the Thyroid Gland in Pediatric Chest Radiography. Int J Pediatr 2016:4 (7):2183-2191.

[13] Harinder Paul Singh. Occupational Radiation Protection Method in International Radiology. International Journal of Community Health and Medical Research. 2016:2 (1):20-3.

[14] National Council on Radiation Protection and Measurement. Radiation Protection in Dentistry NCRP Report No.145. Bethesda, National Council on Radiation Protection and Measurement, 2003.

[15] Badrian H, Sheikhi M, Abdinian M. Knowledge, Attitudes and Performance of Dental Practitioners in Isfahan-Iran about Biologic Effects of Ionizing Radiation and Protection Against them in 2011. J Mash Dent Sch 2011:37 (1):19-26 (Persian).

[16] Javadzadeh A, Alipour H. Knowledge of general dentists about radiation protection in oral radiographic examination in the city of Rasht-Iran in 2009. J Mash Dent Sch 2011:35 (1):23-32 (Persian).

[17] Chui Sung Hyun, Park Jung Eun, Chun Woon Kwan, Ju Yong Jin, Yang Nam Hee, Dong Kyung Rae. Usability evaluation through gonad shielding production of pediatric patient by gender and age rating. Journal of Radiation Industry; 2015.9 (2). 69-75.

[18] Maria T. Pediatric radiation protection. Raissaki in European Radiology 2004:14 (Supp11): 74-83.

[19] Frantzen MJ, Robbern S, Postma AA, Zoetelief J, Wildberger JE, Kemerink GJ. Gonad shielding in padiatric pelvic radiography: disadvantages prevail over benefit. Insights Imaging2012:3 (1): 23-32.

[20] Karami V, Gholami M. A Systematic Review on the Prevalence of Shielding in Patient Undergoing Diagnostic Xray Procedures in Iran. Proceeding of the $7^{\text {th }}$ internal congress Student Research: 2015 march 1: Jundishapur University of Medical Sience, Ahvaz, Iran: 2015. p. 249.

[21] VahidKarami, Mansour Zabihzadeh. Radiation Protection in Diagnostic X-ray Imaging Departments in Iran: A Systematic Review of Published Articles. J Mazandaran Univ Med Sci 2016:26 (135):175-188 (Persian).

[22] Shahbazigahrooiy D. Quality control of diagnostic radiology equipment in hospitals of ChaharmahalBakhtiari Province (2005-2006). Journal of Shahrekord University of Medical Sciences 2005:5 (4):11-18 (persian).

[23] Keikhai-Farzaneh M-J, Shirin-Shandiz M, Vardian M, Deevband M-R, Kardan M-R. The quality control of diagnostic radiology devices in hospitals of Sistan and Bluchestan, Iran. Indian Journal of Science and Technology 2011:4 (11):1458-1459.

[24] Tamjidi A. Principles of radiation protection in radiology centers in the province South, fourth year the first issue (2001) 47-52. 